\title{
An Agenda for Action toward a New International Language Order
}

\author{
Chong-yeong Lee \\ Universal Esperanto Association
}

\begin{abstract}
The present study argues for the need for an international auxiliary language besides national languages. There are three essential conditions to be qualified as an international common language: ethnically neutral, easy to learn, and sufficiently functional. Given this, it is shown that Esperanto is the language that can be adopted as the international auxiliary language.

In order to counter the heavy tide of the linguistic imperialism of English which dominates the world and, to foster linguistic democracy to protect national languages from being devoured by English, it is essential to campaign for establishment of a just and democratic new international language order.
\end{abstract}

\section{Introduction}

"Today, assembled here are not French and British, neither Russians and Polish, but human and human." This is what Dr. Lazaro Ludviko Zamenhof, the initiator of Esperanto, an international language, said in his speech at the opening ceremony of the 1st World Esperanto Congress held in 1905 in France; this is what any international conference should be and can be if all the participants speak a common neutral language.

Dr. Inazo Nitobe, Under-Secretary General of the League of Nations, in his report to the Secretary General of the League of Nations concluded by saying, "That the world's progress is impeded by linguistic barriers is a statement no longer to be despised as a platitude. It embodies a serious menace to the cause of peace...," 
Additionally, he asked, "The League may well ask... Is an international auxiliary language possible? If so, what should the League do?"

Since he asked questions, 75 years have passed, which are still valid. Based on the 110 years of experience since the creation of Esperanto, an international auxiliary language, this paper will attempt to answer the questions asked 75 years ago.

\section{Is an International Auxiliary Language Possible?}

There are three essential conditions necessary to be qualified as an international common language. First, it must be ethnically and politically neutral. Second, it must be easy to learn so that anyone can learn it without difficulty. Third, it must be sufficiently functional as a living language of human being. Esperanto has proved that it has met these three conditions.

After 110 years of use by millions of people in 120 countries in the world, the idea of an international auxiliary language represented by Esperanto is no longer a trial project but a fact. Every year over 300 new titles, both original and translations appear in wide ranging fields. Recent publications include; $A$ Search for the Perfect Language by a world-famous Italian linguist Umberto Eco. The Decameron by Giovanni Boccaccio of Italy, and The Dream of the Red Charmer, by Cao xueqin of China, and Vast World and Many Works To Do, by Kim Woo Choong. Over 100 magazines and journals are published regularly in Esperanto, including Monato, the news magazine, El Popola Cinio (From the People's China), the lavishly illustrated monthly magazine from China, Heroldo de Esperanto, an independent bi-weekly newspaper, and Esperanto, the monthly official organ of the universal Esperanto association. Radio stations in Austria, Brazil, China, Cuba, Estonia, Hungary, Italy, The Vatican, and Poland broadcast regularly in Esperanto.

Computer networks are the fastest growing means of communication for which Esperanto is the most convenient for 
communicating among diverse nationalities. There are more than 30 libraries and museums of Esperanto throughout the world. The library of the British Esperanto Association has a collection of more than 20,000 items. Other large libraries include the International Esperanto Museum in Vienna, the Hodler Library at the Universal Esperanto Association's headquarters in Rotterdam, and the Center for Documentation and Research on the International Language in La Chaux-de-Fonds, Switzerland.

With such diversified activities, literatures and speakers throughout the world, the international language Esperanto is no longer a project. It is a fact and reality, and is already a social phenomena.

\section{If It Is Possible, How Far Is It Practical?}

The most vivid example which shows the practicality of the international language is its annual congress. The world congress has been held every summer since 1905, except during the two world wars periods. The latest one was the 84th World Esperanto Congress held in Berlin, Germany in August 1999. The world congress will be held in Tel Aviv, Israel, in August 2000 and in Zagreb, Croatia in 2001. The congress was held three times in Asia: Tokyo in 1965, Beijing in 1986, and Seoul in 1994. Typically around 2,000-3,000 people from over 60 countries participate in the one-week congress. This is the only large-scale international meeting where no interpreters are used. Via Esperanto, the participants take part in speeches, committee meetings, debates, university lecturers, professional group discussions, plays, music, dances, excursions, and friendly chatting, without interpreters. Along with the World Esperanto Congress, the International Youth Congress is also held every year. In fact, it would be technically impossible to conduct an international gathering of such magnitude, without an international common language, even if interpreters were available. Anyone who has ever experienced an Esperanto congress immediately sees that the idea of an international common language 
is not only possible, but very practical.

The Universal Esperanto Association, based in Rotterdam, Netherlands, has nearly 30,000 paid members in over 80 countries; there are Esperanto speakers in about 120 countries. It has more than 60 country-level associations. 40 professional international associations, and 2,000 "delegates" in about 80 countries. The central office of the association receives everyday over 50 letters and electronic massages. All the documentation and correspondences of the association are in one language, Esperanto.

One hundred ten years of use of Esperanto, 90 years of the operation of the Universal Esperanto Association, and 84 annual world congresses held in Esperanto clearly prove the practicality of the international common language.

\section{Is It Advisable to Encourage International Language?}

The first official discussion on Esperanto at an inter-governmental organization was based on a draft resolution proposed to the general assembly of the League of Nations on 9 December 1920, which said;

"The League of Nations... follows with interest the experiments of official teaching of the international language Esperanto in the public schools of some members of the League; hopes to see that teaching made more general in the whole world so that the children of all countries may know at least two languages, their mother tongue and an easy means of international communication; [and] asks the Secretary General to prepare, for the next Assembly, a report on the results reached in this aspect."

The recommendation was placed before the Second General Assembly of the League of Nations in September 1922. The matter was referred to the Committee on Intellectual Cooperation, which discussed the issue in July 1923. After heated discussion and largely influenced by the French delegate, the committee decided not to 
study the question of Esperanto teaching in schools, not to recommend an artificial language to the League, although the Committee "[did] not dispute the practical advantages which would result from the universal adoption of an artificial language." Just before the resolution was put to the vote, Dr. Nitobe, UnderSecretary General of the League, intervened to express a far-sighted fear that when a score of years had passed, and the number of people speaking Esperanto had become greater, "they might hold up any adverse or unfavorable resolution of this Committee as evidence of its lack of wisdom."

However, the plenary session of the League in September 1924 confirmed a recommendation that "Esperanto be recognized as a clear language* in telegraphy. The International Telegraphic Union (ITU) accepted the recommendation and added Esperanto to the list of languages whose use was permitted. This decision has remain unchanged and is still in force.

Twice, the conference of the United Nations Educational, Scientific, and Cultural Organization (UNESCO) passed resolutions favorable to Esperanto. Its 4th Conference, held in Montevideo in 1954, "noted the results achieved with Esperanto in the field of international intellectual interchanges, ... and commissioned the Director General to follow the current development of the use of Esperanto in science, education, and culture, and to cooperate with the Universal Esperanto Association on matters of concern to both organizations."

On the occasion of the 100th birthday of Esperanto, the UNESCO General Conference held in Sofia in 1985 "recognized the great potential which Esperanto showed for international understanding and communication among peoples of different countries..., requested the Director General to continue to follow the development of Esperanto as a means for improving understanding among different peoples and cultures, invited the state members to mark the 100th year of Esperanto, and recommended that the international nongovernmental organizations join this jubilee and study the possibility of utilizing Esperanto as a means for 
disseminating among their members information, including the activities on UNESCO."

In 1993, the 27th General Conference of UNESCO again discussed Esperanto. Unfortunately, a favorable resolution proposed by Italy was not voted but remained as working document.

Often head of states, the Secretary General of the U.N. and the Director General of UNESCO send messages to world Esperanto congresses, or participate in the congress in person. In 1977, the Director General of UNESCO Mr. MacBow himself attended the opening ceremony of the 62nd World Esperanto Congress held in Raykjavik, Iceland, and encouraged the Esperanto movement. In 1990, President Fidel Castro of Cuba participated in the opening ceremony of the 75th congress held in Havana. In 1998, Mr. Boutros Ghali, Secretary General of the newly formed Agency of Francophonie, was invited to participate in the 83rd congress to be held in Montpelier, France.

\section{Isn't English Already the International Common Language?}

There are three kinds of linguistic inequality that are particularly pervasive and problematic in the contemporary world: linguistic non-communicability, linguistic injustice, and linguistic cannibalism. Linguistic non-communicability caused by language differences places smaller or weaker peoples at economic, social, and legal disadvantage. Linguistic injustice is caused when politically influential language is imposed upon others, or when linguistic injustice is actually promoted by state's legal and political systems, for instance, when the use of particular language is outlawed, or when they are deliberately excluded from the education system, which was the case of the Korean language under Japanese rule in the past. Linguistic cannibalism is the most dangerous language problem of all. This is the tendency of ethnic languages of wider communication, such as English, to impose themselves in the place 
of others, submerging and impoverishing local cultures. But the most critical and even destructive problem is the fact that the ethnic language is cannibalistic. It devours other national languages in the fields of international meetings, commercial trades, sciences, technologies, and tourism. Ironically, the true language problem in the United Nations and the European Union is not lack of communication between delegates due to language differences but the increasing dominance of a single ethnic language over all other languages and becoming a defacto international common language. The problem is that U.N. "does not admit" the existence of a language problem, or more precisely expressed, it does not touch the language problems, because it is "a bonb" according to a German diplomat. The situation is more serious in European Union, where 11 languages (very soon it will be 15 languages) are equally used as "official languages."

The linguistic cannibalism has reached a dangerous level. Proliferation of linguistic and cultural cannibalism by an influential single ethnic language has already stimulated representatives of politically strong languages to defend themselves against the linguistic hegemonies. They have started to establish various counter measures.

This means that an ethnic language, such as English, no matter how influential it is in the international communication, will not be, and cannot be accepted as the official international common language.

\section{An Agenda for Action}

There is no question of the need for an international auxiliary language beside national languages for humanistic, cultural, political as well as economic reasons. Times have changed, but the basic situation which requires an international auxiliary language remains the same. Rational analysis from any directions clearly indicates the need for a "neutral international auxiliary language" for international communications. 
What is lacking is political will and pressure to adopt an international auxiliary language. Such actions should be initiated by political intergovernmental organizations, of which the United Nations and the European Union are the leading ones.

Because of the pressing need to solve language problems in Europe, efforts are being made by the European Parliaments, the Council of Europe and the European Union to find agreeable solutions. The Working Group on Language Problems actively sought a solution in October 1998. The recommendations of the meeting were presented to the Council of Europe, through the European Parliament. The monitoring network of Esperanto indicated that about $18 \%$ of the 627 members of the European Parliament are "more-or-less" in favor of adopting Esperanto as the international auxiliary language of the European Union. If an international organization adopts an international auxiliary language, probably the European Union would be the first one. In this sense, Europe is a strategic area for the adoption of an international auxiliary language.

However, the United Nations lag behind in the language issue. The recent reform programme of the U.N. considered various programmes to improve its operational efficiency; it did not touch the language issue, because language problems do not exist." In order to provide political impetus, it is necessary to stimulate the U.N. to discuss the language issue. As a follow up of discussions on the language issues, the U.N. may appoint a working group or a Sub-Committee to study the current international language problems, to evaluate existing international common languages, to test their effectiveness and practicability, and to report to the ECOSOC General Assembly on the findings and the recommendations. Politically and economically influential but linguistically disadvantageous countries, such as German and Japan, and even China and France, can play a leading role in mandating the U.N. to discuss the language issues.

In the field of linguistic aspects of human rights, the U.N. High Commissioner for Human Rights already recognizes the language 
problems which affect the human rights, and supported Universal Esperanto Association to organize a symposium on "Language and Human Rights" on 28 April 1997 in the Palace of Nations, the official U.N. building in Geneva.

If any government succeeds in persuading the U.N. to discuss the language issue, and if the U.N. arrives at a rational resolution, it will be one of the greatest moments in the human history, and the action will be recognized as "evidence of wisdom."

\begin{tabular}{|c|c|}
\hline $\begin{array}{l}\text { Sur neutrala lingva fundamento, } \\
\text { Komprenante unu a alian, } \\
\text { La popoloj faros en konsento, } \\
\text { Unu grandan rondon familian, } \\
\text { ("La Esperto", L. L Zamenhof.) }\end{array}$ & $\begin{array}{l}\text { On the neutral linguistic foundation, } \\
\text { Understanding each other, } \\
\text { The peoples will form in consent, } \\
\text { One great circle of family }\end{array}$ \\
\hline
\end{tabular}

\section{References}

Boccaccio, Giovanni. 1995. Dekamerono, Kooperativo de Literatura Foiro. Lausanne.

Cao, Xueqin. 1995. Rugdoma Songo. Cina Esperanto-Eldonejo: Beijing, China.

Eco, Umberto, 1994. La Sercadodela Perfekta Lingvo. Edistudio, Italia.

Kim Woo-Choong. 1998. VasaslaMonda Multas Laboro:Seoul, Korea.

Lapenna, Ivo. 1970. "The Common Language Question before International Organizations," LaMondaLingoProblemo2 pp. 65-128.

Lee, Chong-Yeong. 1998. "'Lingvo kaj Homaj Rajtoj," a speech at the International Seminar on the Language and Human Rights. UN:Geneva.

Inazo, Nitobe. 1992. "Report on the Esperanto Congress in Prague, 31 July - 
6 Aug 1921," TheLeaguegfNations; OffiadJama3,pp. 295-298.

UNESCO. 1954. ResodwiongtheGeneralConferencegfUNESCOMontevideo.

UNESCO. 1985. ResoldiongtheGenerdConferencegfUNESCOSofia. 